\title{
Research on the Influencing Factors of Social Network on Community Endowment of Elderly in Rural Areas of Shaanxi
}

\author{
Wang Ping, Liu Jiao*, Li Yaping \\ School of Management, Xi'an University of Science and Technology, Xi'an, China
}

Email address:

853209225@qq.com (Liu Jiao)

${ }^{*}$ Corresponding author

To cite this article:

Wang Ping, Liu Jiao, Li Yaping. Research on the Influencing Factors of Social Network on Community Endowment of Elderly in Rural Areas of Shaanxi. Humanities and Social Sciences. Vol. 5, No. 5, 2017, pp. 184-191. doi: 10.11648/j.hss.20170505.14

Received: September 13, 2017; Accepted: September 23, 2017; Published: September 29, 2017

\begin{abstract}
On the basis of the data from "Shaanxi rural elderly community care situation questionnaire" in August 2015, this paper analyzes the support statement of the elderly in rural areas of Shaanxi province profoundly, and uses multivariate logistic regression analysis to investigate the influencing factors of the community endowment of the elderly in rural areas. Accordingly, to identify the real needs of the elderly in countryside. The research result reveals that these who have higher economic self-support ability are more inclined to choose community endowment. By contrast, those old person with a lower economic capability are willing to choose family endowment. At the same time, the choice to community endowment of the rural elderly is also restricted to the factors of old-age pension demand and supply.
\end{abstract}

Keywords: Shaanxi Rural Area, The Elderly, Community Endowment, Social Network, Influencing Factors

\section{Introduction}

For a long time, the support of the elderly endowment in rural areas China is mainly provided by their family. But with the implementation of the family planning policy, China's family structure and family size gradually grow to miniaturization and core-trend. At the same time, the lack of pension funds of the elderly in rural areas in our country, the total ignorance of the pension demands and coupled with the rural areas of old-age service facilities and incongruous input-output ratio caused the imbalance of China's rural areas endowment service supply and demand. The situation is not optimistic. [1] Community endowment is a new type of pension model gradually developed on the basis of the weakening of rural family's pension function and the insufficiency of institution endowment. It is a kind of elderly endowment model mainly based on the home care, and the community institution endowment secondly. [2] Community endowment inherited the advantages of the family pension and had the nature of the socialization. And at the same time it had many characteristics such as broad coverage, low cost and humanization. [3] Community endowment takes community as a platform and integrates the government, society and community resources to establish a specialized service agencies and service teams for the elderly living in the home to provide material support, life care, spiritual comfort and other services. [4] Community endowment services not only the family, friends, neighbors, volunteers and so on within the community, [5] but also the formal and informal organizations outside the community. The implementation of community endowment services can reduce the time of the elderly in private nursing homes and hospitals, save money, and also can enhance the elderly(especially the young elderly) survival rate, cognitive ability, living ability, physical health and life satisfaction. It is an effective way of endowment. [6-9] The establishment of a community endowment service system plays a vital role in alleviating the burden on the state and making up for the lack of support for families and institutions. [2] And community endowment services can not only effectively alleviate the supporting issues of the elderly, improve the quality of life of the elderly in old age, but also can allocate the social resources effectively. So rural areas should vigorously promote the community endowment services. [5, 10-14] 
At present, most of the domestic research on community endowment is focused on the problems and suggestions of community endowment practice, but neglects the assessment of old-age needs and community endowment patterns. Therefore, based on the systematic understanding of social network and community endowment, this paper puts forward the research framework of the analysis of influencing factors of rural community in Shaanxi province from the perspective of social network, analyzes and discusses the influence of characteristics of the network on the elderly endowment in rural areas by Logistic regression analysis. And finally put forward the corresponding policies and suggestions for the conclusion of this paper, and light the direction to a further study in the future.

\section{Hypothesis}

There are many studies on the situation of pension in rural communities, but there are few studies discuss from the perspective of social networks. Social networks play a key role in people's daily lives, and good social networks are beneficial to people's physical and mental development. There are many factors that affect the willingness of the elderly in the rural areas. The factors include their characteristics, family characteristics, income status and community environment have an important influence on the willingness of the elderly in rural areas. Due to age reasons, most of the rural elderly cannot go out to work. They live in a single environment. Their family and community occupy a large position in their lives. The larger the social network of the rural elderly is, the more people they would have relationship with. And for the rural elderly, these are mostly their friends and neighbors. Friends occupy an important position in their social circle. They can find them to talk when they were in a bad mood and find their help when life was difficult to continue. Neighbors would give them a great support and help in the work. Rural elderly sometimes will feel depressed in the cause of little nothings in the life and it is the neighbors who usually chat with and comfort them. They can be relaxed and decrease the depressed mood. This paper put forward some hypotheses about the network scale as followings:

Hypothesis 1: The larger the network scale is, the stronger willingness of the community endowment will have by the elderly.

If the aged has a broader social network in their lives, they would have less dependence on their children and be more independent in their daily lives. And the broader social networks can sometimes provide them great support and help. In addition to the size of the network, there are more important quality factors that influence the willingness of the community endowment by the elderly in rural areas, which called joint relationship strength. If rural elderly are closer and know each other longer in their work and life, they will ask them for help who are in a better relationship at the first time in the face of difficulties. In this paper, the author puts forward the following hypothesis on the depth of relationship between the network members:

Hypothesis 2: The deeper relationship between the elderly and the network member is, the stronger willingness of community endowment will the elderly have.

The frequency of the interaction between rural elderly and network members shows that these older people are more willing to communicate with each other and find the object of talk with. These interactive members will also provide more support and help to their lives. The older people are more inclined to be independent and have stronger willingness of community endowment. On the contrary, if the elderly and the network members have not know long indeed, the relationship is not intimate and the interaction is not frequent, it proves that the network members do not get the trust of the elderly. The elderly will not get any help from these network members in their difficult time. The elderly will be more dependent on their own and their families. And they will have slight willingness of community endowment. This paper put forward a hypothesis about the frequency of the relationship as follows:

Hypothesis 3: The more frequent their relationship is, the stronger willingness of community endowment will the elderly have.

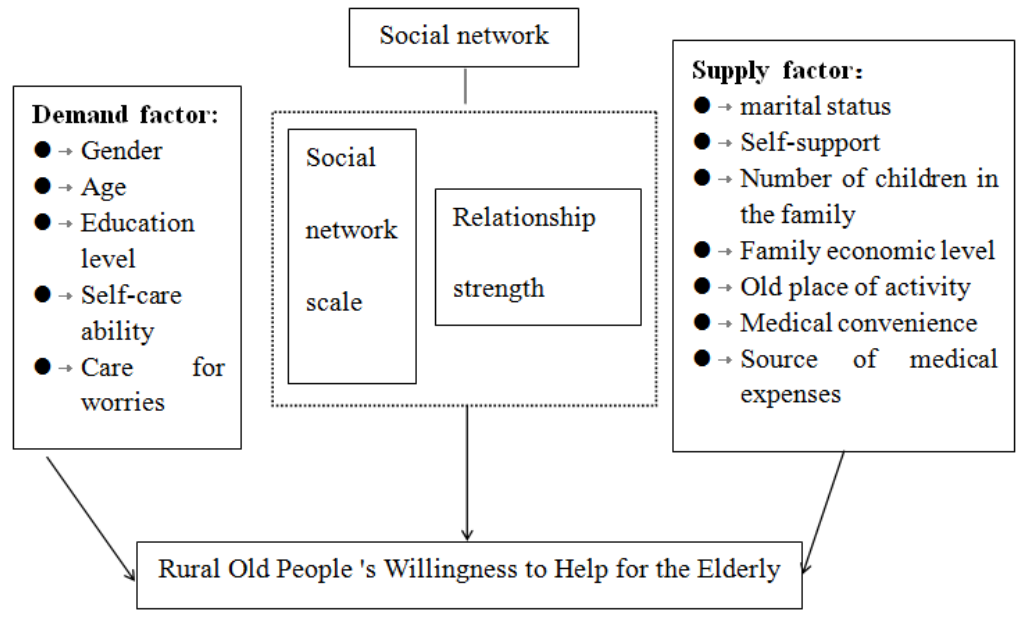

Figure 1. Analysis of the Impact of Social Networks on the Willingness of the Elderly in Rural Areas. 


\section{Data and Methods}

\subsection{Data Sources}

Data involved in this study are mainly from the data this research group collected in the questionnaire. The study used questionnaire investigation and selected part of the villages from Hanzhong, Ankang, Baoji, Weinan, Yan'an and Yulin. The survey was conducted in the rural areas of Shaanxi Province over the age of sixty. It is required that these elderly people have a clear mind and can express their own consciousness independently. The survey is mainly carried out based on rural households in Shaanxi Province as a unit of research, through face-to-face questionnaire survey. In order to test the effectiveness of the questionnaire design, the group did a questionnaire survey issued a total of 20 questionnaires in July 2015 in Xi'an, Shaanxi Province, Lintong District, Xiekou Township, Liu Shu Village. Though the pre-investigation to delete and supplement the part of the questionnaire, making the questionnaire more reasonable and perfect. In August, 2015, the project group organized a total of six investigators to the survey area Baoji, Weinan, Hanzhong, Ankang, Yan'an, and Yulin, six areas of the village for a period of 2 weeks of rural elderly households' survey jobs. They randomly selected three townships in the survey area, and each town to take two villages to carry out the research. The survey uses a question and answer form and the investigators fill in the questionnaire survey. This questionnaire covers a wide range of places. And to some extent, the survey can reflect the actual situation on rural elderly' pension status in Shaanxi Province. The survey data are from the six regions of Shaanxi Province, 13 villages in 260 rural elderly surveys, a total of 260 questionnaires issued, due to the questionnaire to fill in the form of one to one question and answer, 260 questionnaires, which valid questionnaire 246 , the efficiency of the questionnaire was $94.6 \%$. The basic situation of the elderly in the effective sample, the basic situation of the family and the basic situation of the pension as shown in Table 1.
The statistical results in Table 1 show that in terms of gender characteristics, the proportion of sex between men and women was equal, women accounted for $58.13 \%$, slightly more than men which in older women longer life expectancy than men have a certain relationship. According to the survey data, there are thirteen male of the thirty-two older than 80 years old. In terms of age composition, most of the elderly aged under 80 years old, mainly concentrated in $60 \sim 70$ years old, 80 years old above accounted for only $13.01 \%$. Samples from the level of education, the majority of the elderly only accepted the primary and the following education, including received high school education (secondary) of elderly people $(5.28 \%)$, and received junior college or above education of the elderly is only $2.44 \%$, visible rural old people by education degree is generally low, and the education development in rural areas lag behind. Marital status, samples of most elderly married spouses and alive, in $77.64 \%$, and the death of a spouse or unmarried accounted for $22.36 \%$.In terms of number of having children, there are 3 or 4 children family is more, accounted for $46.34 \%$. It has certain relation about the inherent concepts of "raise children for retirement safeguard" and "the more sons, the more blessings". But the survey also found that the proportion of children of migrant workers is bigger also. It proves that rural households are still quite a proportion of the labor outflow phenomenon. From the point of living way, at present there are more than $53.25 \%$ of the elderly live together with their children, and $46.75 \%$ of the elderly living alone or living with a spouse. At present the separation phenomenon of rural elderly people and their children is common. The elderly do not living with their children are in a higher proportion. This kind of phenomenon is especially apparent in young elderly or the older people with a better economic condition. With the development of the society, two different generations living preferences are changing. The elderly parents and adult children living separation can reduce the conflicts to some extent, thus gradually accepted by the two generations.

Table 1. Survey Sample Basic Situation $(N=246)$.

\begin{tabular}{|c|c|c|c|c|c|}
\hline Basic Characteristic & Frequency & Percentage (\%) & Basic Characteristic & Frequency & Percentage \\
\hline Gender & & & Economic sources & & \\
\hline Male & 103 & 41.87 & Farmers' income & 39 & 15.85 \\
\hline Female & 143 & 58.13 & Children given & 100 & 40.65 \\
\hline Age & & & Retirement or pension & 57 & 23.17 \\
\hline $60 \sim 69$ & 125 & 50.81 & Government subsidies,social donations & 19 & 7.72 \\
\hline $70 \sim 79$ & 89 & 36.18 & Personal savings & 27 & 10.98 \\
\hline $80 \& \uparrow$ & 32 & 13.01 & Non-agricultural employment & 4 & 1.63 \\
\hline Primary school and below & 187 & 76.02 & Fully able to take care of themselves & 20 & 8.13 \\
\hline Junior high school & 40 & 16.26 & Part can take care of themselves & 177 & 71.95 \\
\hline High school（Polytechnic school） & 13 & 5.28 & Completely unable to take care of themselves & 49 & \\
\hline College and above & 6 & 2.44 & Daily help people & & \\
\hline Marital Status & & & Spouse / child & 179 & 72.76 \\
\hline Married & 191 & 77.64 & Neighbors / relatives & 38 & 15.45 \\
\hline No spouse & 55 & 22.36 & Friends / fellow & 13 & 5.28 \\
\hline Number of children & & & Village cadres and so on & 16 & 6.50 \\
\hline
\end{tabular}




\begin{tabular}{|c|c|c|c|c|c|}
\hline Basic Characteristic & Frequency & Percentage (\%) & Basic Characteristic & Frequency & Percentage \\
\hline Three or four & 114 & 46.34 & Have & 193 & 78.46 \\
\hline Five and above & 25 & 10.16 & No & 53 & 21.54 \\
\hline Living style & & & Community mutual help & & \\
\hline Live with your children & 131 & 53.25 & Willing & 196 & 79.67 \\
\hline $\begin{array}{l}\text { Do not live with their children } \\
\text { Health status }\end{array}$ & 115 & 46.75 & $\begin{array}{l}\text { Do not want to } \\
\text { Life satisfaction }\end{array}$ & 50 & 20.33 \\
\hline $\begin{array}{l}\text { Health status } \\
\text { Good }\end{array}$ & 52 & 21.14 & $\begin{array}{l}\text { Life satisfaction } \\
\text { Satisfaction }\end{array}$ & 147 & 5076 \\
\hline General & 123 & 50.00 & Not satisfied & $\begin{array}{l}14 / \\
99\end{array}$ & 40.24 \\
\hline Very bad & 71 & 28.86 & & & \\
\hline
\end{tabular}

Source: August 2015 "Shaanxi rural elderly community pension situation questionnaire" sample survey.

\subsection{Variable Design}

This paper investigates the influence of social network of rural elderly in rural areas on the status of community pension in China. By constructing the Logistic regression model, discusses the community pension situation of the elderly in the rural elderly. The dependent variable is the community's willingness to endow the community for the second class. The independent variables are two characteristics of the network size and the joint strength of the social network, and the control variables are selected from the pension demand variable and the pension supply variable. The definition and assignment of the specific variables in the model are shown in Table 2 and Table 3 respectively. Table 4 shows the descriptive statistical analysis of the variables in the study of the impact of social networks on the situation of rural elderly in Shaanxi rural areas.

\subsubsection{Dependent Variable}

Community Willingness (Y1): The choice of community pension intention for rural elderly in the field survey was divided into two categories. Ask the elderly on the "if the village set up elderly organizations, are you willing to join?" Who choose the answer like "very like to" and "like to" are intend to choose the community endowment. Y1 is 1 . Those who choose "general" or "whatever" are unwilling to join. Y1 is 0 .

\subsubsection{Independent Variable}

Network size (NS): Social network size refers to the number of members of the network owned by the surveyed individuals, which reflects the quantitative characteristics of the social network, and it also represents, to some extent, the amount of social capital owned by the individual center. It is regarded as a key feature of the individual social network. The size of the individual network is expressed by the number of network members associated with the individual. The greater the number of network members is, the larger the size of the individual's network would be; otherwise, the smaller. This paper chooses the quantitative characteristics of the social network as the independent variable to analyze its impact on the rural elderly in the elderly. In this study, the maximum number of network members designed for the questionnaire is 5 , and the network scale is in the range of 0-5. The larger number does the network size is, the broader the social network of the rural elderly is; whereas, the smaller.

The network relationship strength (TS): the relationship between the joint strength is the quality characteristics of the social network. This paper uses the joint strength as another independent variable to study its impact on the rural elderly pension. The strength of the network relationship refers to the strength of the network relationship between the surveyed and the network members. The quantization is mainly measured by the dimension scale which reflects the intensity of the network relationship. In this study, the authors used the three dimensions of cognitive time, interaction frequency and intimacy to measure the network intensity of rural elderly. In this paper, the three problems in measuring the strength of social network relationship are the three aspects of knowing the length of time, the frequency of interaction and the intimacy. The question of how long is the knowledge of "how long do you know him?" The answer to the question is "1 year" $=1, " 1-3 "=2, " 3-6$ years" $=3$, "6 years and above" $=4$. The frequency of interaction is "How long does it take?" The answer to the score is "very little"= 1 , "every year"= 2 , "monthly" = 3, "weekly"=4, "daily" = 5; "How close you and he (her)?" The answer to the option score is "not intimate" = 1 , "not too close" = 2, "general" = 3, "more intimate" $=4$, "Intimate" $=5$. The higher score of the three questions is, then the higher the degree of interaction between the elderly and the members of the network, the more frequent the frequency of interaction, the higher the degree of intimacy, whereas, less intimate. In order to obtain the specific score of the joint strength, this paper uses the principal component analysis method to simplify the three dimensions of cognition time, interaction frequency and intimacy. The result is two effective factors, which are named frequency factor and depth factor. The factor is mainly related to the frequency of interaction, and the depth factor is mainly related to the time and intimacy. In this paper, we study the two variables of depth factor (TS (D)) and frequency factor (TS (F)) as the independent variables of network quality to study the influence model of joint intensity on rural elderly.

\subsubsection{Control Variables}

Control variables are divided into pension demand variables and pension supply variables. The variables of the old demand include: gender (G), age (A), education level (E), self-care ability (L) and future care anxiety (F). There are three types of variables: (1) Self-supply factors, including marital status (MS) and self-support (SS). (2) Family supply factors, including: family number of children (FN), family economic level (FE) 2 variables. (3) Community supply factors, including: the elderly activities (AP), medical 
convenience (MC), medical expenses (ME) 3 variables.

Table 2. Variable Definition Table.

\begin{tabular}{llll}
\hline Variable symbol & Variable meaning & Variable symbol & Variable meaning \\
\hline Y $_{1}$ & Community willingness to support the community & C & Care for worries \\
NS & Network size & SS & Self-support \\
TS (F) & Relationship frequency & FI & Family economic level \\
G & Gender & MP & Old place of activity \\
A & Age & MC & Medical convenience \\
E & Education level & ME & Source of medical expenses \\
S & Self - care ability & SM & Marital status \\
\hline
\end{tabular}

Table 3. Variable Assignment Table.

\begin{tabular}{|c|c|c|}
\hline Variable type and name & & Variable meaning and assignment \\
\hline Explained variable & $\begin{array}{l}\text { Community willingness to support the } \\
\text { community Y1 }\end{array}$ & Whether it is willing to join the elderly organizations: yes $=1, \mathrm{no}=0$ \\
\hline \multirow{3}{*}{ Explanatory variables } & Network size NS & Network size: $0-5$ \\
\hline & Relationship depth TS (D) & $\begin{array}{l}\text { Know time: } 1 \text { year or less }=1,1-3 \text { years }=2,3-6 \text { years }=3 \text {, } \\
6 \text { years and above }=4 \\
\text { Intimacy: Very not intimate }=1 \text {, Not very intimate }=2 \text {, General }=3 \text {, Compare } \\
\text { intimate }=4 \text {, Very intimate }=5\end{array}$ \\
\hline & Relationship frequency TS (F) & Contact frequency: Seldom $=1$, Per year $=2$, Per month $=3$, Weekly $=4$, Every day $=5$ \\
\hline \multirow{6}{*}{ Pension demand variable } & Gender G & Male $=1$, Female $=0$ \\
\hline & Age A & Year old \\
\hline & Education level $\mathrm{E}$ & $\begin{array}{l}\text { Primary school and below=1, Junior high school=2, High School (Secondary)=3, } \\
\text { College and above }=4\end{array}$ \\
\hline & Self - care ability S & $\begin{array}{l}\text { Whether or not need someone to take care: Completely needed }=1 \text {, Partly needed=2, } \\
\text { Partly needed }=3\end{array}$ \\
\hline & Care for worries $\mathrm{C}$ & $\begin{array}{l}\text { Whether or not worried that no one care: Never considered }=1 \text {, do not worry }=2 \text {, a little } \\
\text { worried }=3 \text {, very worried }=4\end{array}$ \\
\hline & Marita & Whether or not spouse: $Y e s=1, \mathrm{No}=0$ \\
\hline \multirow{6}{*}{ Pension supply variable } & Self-support SS & The main economic sources depends on their own (or spouse): $\mathrm{Yes}=1, \mathrm{No}=0$ \\
\hline & Number of children in the family FN & The total number of children in the family \\
\hline & Family economic level FI & Last year net income for the family \\
\hline & Old place of activity MP & Yes $=1, \mathrm{No}=0$ \\
\hline & Medical convenience MC & $\begin{array}{l}\text { where go to see a doctor if you ill often: Regardless of it }=1 \text {, Go to the pharmacy to buy } \\
\text { medicine }=2 \text {, Village clinics }=3 \text {, Town (or city) hospital }=4\end{array}$ \\
\hline & Source of medical expenses ME & $\begin{array}{l}\text { All pays }=1 \text {, Child payments, social assistance or government subsidies }=2 \text {, The new } \\
\text { rural cooperative medical reimbursement }=3 \text {, medical insurance }=4\end{array}$ \\
\hline
\end{tabular}

On the basic statistical characteristics of the variables in Table 4 , it should be noted that the maximum and minimum values of the household economic level variables are large and the heteroskedastic problem is likely to occur in the analysis. Therefore, the regression analysis below uses the logarithmic value. The level of the family economy is the lowest monthly household income of 500 RMB last year, up to 8,000 RMB, the lower income of the family because some of the elderly in their own economic income is not considered self-sufficient part of the resulting low value, and income Higher families due to last year, a housing, housing spending so that the value is high.

Table 4. Descriptive Statistical Analysis of variables $(N=246)$.

\begin{tabular}{lllll}
\hline Variable & Minimum & Maximum & Mean & Standard deviation \\
\hline The wishes of community care & 0 & 1 & 0.80 & 0.60 \\
Life satisfaction & 0 & 1 & 1 & 0.42 \\
Gender & 0 & 94 & 68.11 & 0.40 \\
Age & 60 & 4 & 2.34 & 0.49 \\
Education level & 1 & 3 & 2.12 & 0.69 \\
Self-care ability & 1 & 4 & 0.78 & 0.52 \\
Care for worries & 1 & 1 & 0.44 & 0.90 \\
Marital status & 0 & 1 & 2.86 & 0.42 \\
Self-support & 0 & 7 & 2530.49 \\
Number of children in the family & 0 & 8000 & 0.78 & 0.50 \\
Family economic level & 500 & 1 & 2.17 \\
Old place of activity & 0 & 4 & 1.33 \\
Medical convenience & 1 & 3 & 0.95 \\
Source of medical expenses & 1 & & 0.62 \\
\hline
\end{tabular}

Source: August 2015 "Shaanxi rural elderly community pension situation questionnaire" sample survey. 


\subsection{Model Establishment}

In this paper, Logistic regression model is used to analyze and discuss the influence of social network on the old-age pension situation of rural elderly in Shaanxi province. The concrete analysis framework is shown in Figure 1. The specific empirical model is as follows:

$$
\begin{gathered}
\log i t\left(P_{1}\right)=\ln \left(\frac{P_{1}}{1-P_{1}}\right) P_{1}=P\left(Y_{1}\right)=\frac{e^{Z_{i}}}{1+e^{Z_{i}}} \\
\mathrm{Z}_{1}=\beta+\alpha_{1} \mathrm{NS}+\alpha_{2} \mathrm{G}+\alpha_{3} \mathrm{~A}+\alpha_{4} \mathrm{E}+\alpha_{5} \mathrm{~S}+\alpha_{6} \mathrm{C}+\alpha_{7} \mathrm{FN}+\alpha_{8} \mathrm{FI}+\alpha_{9} \mathrm{MP}+\alpha_{10} \mathrm{MC}+\alpha_{11} \mathrm{ME}+\alpha_{12} \mathrm{SM}+\alpha_{13} \mathrm{SS}+\partial \\
\mathrm{Z}_{2}=\beta+\alpha_{1} \mathrm{TS}+\alpha_{2} \mathrm{G}+\alpha_{3} \mathrm{~A}+\alpha_{4} \mathrm{E}+\alpha_{5} \mathrm{~S}+\alpha_{6} \mathrm{C}+\alpha_{7} \mathrm{FN}+\alpha_{8} \mathrm{FI}+\alpha_{9} \mathrm{MP}+\alpha_{10} \mathrm{MC}+\alpha_{11} \mathrm{ME}+\alpha_{12} \mathrm{SM}+\alpha_{13} \mathrm{SS}+\partial \\
\mathrm{Z}_{3}=\beta+\alpha_{1} \mathrm{NS}+\alpha_{2} \mathrm{TS}+\alpha_{3} \mathrm{G}+\alpha_{4} \mathrm{~A}+\alpha_{5} \mathrm{E}+\alpha_{6} \mathrm{~S}+\alpha_{7} \mathrm{C}+\alpha_{8} \mathrm{FN}+\alpha_{9} \mathrm{FI}+\alpha_{10} \mathrm{MP}+\alpha_{11} \mathrm{MC}+\alpha_{12} \mathrm{ME}+\alpha_{13} \mathrm{SM}+\alpha_{14} \mathrm{SS}+\partial
\end{gathered}
$$

Among them, $\beta$ is a constant term, $\alpha_{j}$ is the coefficient, $\partial$ is the residual.

\section{The Results and Discussion}

\subsection{Model Result}

\begin{tabular}{|c|c|c|c|c|c|c|c|}
\hline Variable & Model A1 & Model A2 & Model A3 & Model B1 & Model B2 & Model B3 & Model C \\
\hline Constant & $0.489 * * *$ & $0.388 * *$ & $0.708 * *$ & $1.300 * * *$ & $1.344 * * *$ & $1.842 * * *$ & $1.173 * *$ \\
\hline \multicolumn{8}{|l|}{ Social network } \\
\hline Network size & $0.295 * * *$ & $0.407 * *$ & $0.314 * *$ & & & & $0.332 * *$ \\
\hline Relationship strength (frequency) & & & & $0.114 * *$ & $0.206^{* *}$ & $0.194 * *$ & $0.198 * *$ \\
\hline \multicolumn{8}{|l|}{ Demand factor } \\
\hline Gender & & $0.330 *$ & $0.258^{+}$ & & $0.383 *$ & $0.296^{+}$ & $0.340^{+}$ \\
\hline Education level & & $0.330 * *$ & $0.224 * *$ & & $0.311 *$ & $0.215^{* *}$ & $0.266^{* *}$ \\
\hline Self-care ability & & $-0.562 *$ & $-0.579 *$ & & $-0.571 * *$ & $-0.550 *$ & $-0.534^{+}$ \\
\hline Care for worries & & $0.443 *$ & $0.423^{+}$ & & $0.326^{*}$ & $0.336^{+}$ & $0.394 *$ \\
\hline \multicolumn{8}{|l|}{ Supply factor } \\
\hline Marital status & & & -0.469 & & & -0.506 & -0.485 \\
\hline Self-support & & & $0.147 *$ & & & $0.161 *$ & $0.147 * *$ \\
\hline Number of children in the family & & & $-0.053 *$ & & & $-0.088 *$ & $-0.064^{+}$ \\
\hline Family economic level & & & $0.025^{+}$ & & & $0.001^{+}$ & $0.038^{+}$ \\
\hline Medical convenience & & & $0.063 *$ & & & $0.033 * *$ & $0.048^{*}$ \\
\hline Source of medical expenses & & & $-0.167 *$ & & & $-0.171^{+}$ & $-0.148 * *$ \\
\hline-2 Log likelihood & 245.330 & 234.671 & 230.669 & 247.639 & 238.120 & 231.697 & 228.831 \\
\hline PseudoR ${ }^{2}$ & 0.012 & 0.055 & 0.071 & 0.003 & 0.041 & 0.067 & 0.079 \\
\hline
\end{tabular}

The impact of social networks on the willingness of the community endowment in rural areas uses Stata 12.0 for Logistic regression analysis analyzes the 246 valid samples.

Table 5. Logistic Regression Results of the Impact of Social Networks on the Willingness of the Elderly in Rural Areas (N=246).

Note: $* * * \mathrm{p}<0.001 ; * * \mathrm{p}<0.01 ; * \mathrm{p}<0.05 ;+\mathrm{p}<0.1$

Source: August 2015 "Shaanxi rural elderly community pension situation questionnaire" sample survey.

The model A analyzes the influence of the social network size of the rural elderly on the willingness of the community in the community. In the model A1, the network scale is used as the independent variable and the life satisfaction as the variable into the model. The model A2 is based on the model $\mathrm{A} 1$, adding control variables to the elderly pension demand factors; model A3 is based on the model A2 to join the elderly pension supply factors. The model B analyzes the influence of the social network relational intensity of the rural elderly on the willingness of the community in the community. In the model B1, the two factor depth factors and the frequency factor of the joint strength are used as the independent variables; the community pension intention is the dependent variable. And the model B2 and model B3 are added to the model $\mathrm{B} 1$, and the control variables are added to the old age and the supply factor. The model $\mathrm{C}$ is the whole model, the network size, the depth factor and the frequency factor as the independent variable, the old age demand factor and the supply factor as the control variable, and discusses its influence on the dependent society. Logistic regression 
analysis results are shown in Table 5.

\subsection{Discussion}

The results of model A1 show that the social network size of rural elderly has a significant positive impact on the willingness of the community endowment in the elderly, that is, the larger the network size is, the stronger the old-age community will be, and the weak will be. The results of model B1 show that the relationship between depth and intensity of social network is positively correlated with the willingness of community endowment, but it is not significant, and the frequency factor of joint intensity has a significant positive correlation with community willingness. The higher the depth factor and frequency factor, the higher the depth and the higher the frequency, because the relationship between the depth factor and the frequency factor score is higher, so the older people and the social network members are connected with each other more frequently, the greater the probability of the elderly participating in the community pension. This might because the elderly and network members to contact more frequently, each other to each other to support and help the more opportunities, such as network members occupy a larger proportion of neighbors, relatives and friends, can help each other in life and care. However, for the depth of the relationship between the depth factor, the elderly and the network members know the longer the relationship between the more intimate, the probability of participation in community pension is not high. This may be in the network members to know the longer and more intimate members of the elderly are mostly children and spouses, these people are family members, when the family encounter difficulties and frustration most need to face the common face of the elderly It can only be mentally comforted but not substantive help, so the relationship between the depth of the depth factor on the elderly community will not have a significant impact on the pension.

The results of models A2, A3, B2, B3 and C show that there is a significant positive correlation between gender and educational level variables and community willingness to be used in rural elderly pension demand, and age is significantly negatively correlated with community willingness for old age. People in the community than women choose the community more likely to pension; older people more receptive to the community pension; the higher the degree of education, the idea is more open, then choose to participate in community pension probability is greater. In addition, the future care concerns, self-care ability and other variables also passed a significant test, indicating that the needs of life care is also affecting the elderly in rural areas to participate in community pension important factor. But the effect of the two symbols and common sense of the opposite direction, the possible explanation is that the degree of concern for future care reflects the elderly to obtain the possibility of children to take care of the understanding, and the community pension preference for rural life in the future there is a certain care worries; and the statistical characteristics of the self-care ability of life show that most of the rural people's self-care ability is strong, only a few people in life need others to care, and these people may regard themselves as the burden of the family, and inclined to choose the community pension.

\section{Conclusion}

Rural community pension is the development trend of the future socialization in rural areas. But by all aspects of the constraints, most rural elderly people cannot really achieve community pension. This paper analyzes the social network and community pension status of the rural elderly in Shaanxi province, and discusses the factors influencing the participation of the rural elderly in the community in the rural areas from the perspective of social network, in order to study the factors influencing the rural elderly in the community pension. The study draws the following conclusions:

First, in the aspect of the family, the supports of parents pension from their children are became softer and the spiritual support the child provides is less than material support. It shows that part of the elderly have a big gap in the basic survival. They need the society and children give more material support, so that the elderly can be safe in his later years.

Second, on the individual side, some rural elderly people are still engaged in agricultural or non-agricultural labor, the degree of dependence on their children has been reduced. This part of the rural elderly can better self-support, and basically able to achieve "self-sufficiency" pension.

Third, in the community aspect, as most of the villages are limited by economic conditions, the construction of pension facilities behind, pension organizations and lack of public activities, the community's support for old-age support is weak. That indicates that the government's rural elderly pension policy and intensity are not as strong as us thought that it would be. So the government should further increase the rural elderly infrastructure and pension policy advocacy.

Fourth, these older people with a higher level of economic self-protection in rural areas are more likely to choose the community pension. On the contrary, self-support capacity of the rural elderly are inclined to choose the family pension. This is because the rural elderly choose community pension is also restricted by pension needs and pension supply and other factors.

The rural old-age endowment undertaking has a great significance to the sustainable development of China's economy and the construction of a harmonious socialist society. With the increasing background of aging, the weakening of family pension function and the lack of institutional pension, the use of existing resources to improve the rural community endowment system construction. It is helpful for the development of rural endowment in China. How to make the old rural elderly worry nothing and never worry about the pension problem is a big problem placed in front of the state and all levels of government in the top priority. With the implementation of the new rural policy and the state take the elderly endowment in rural areas seriously, China's rural care cause will on a new journey in the future. 


\section{Fund Project}

A Study on the Dynamic Evolution and Family Support Policy of Rural Old People 's Livelihoods and Benefits (71573207) ;A Study on the Influence of Children 's Migration on the Old-age and Health Status of Rural Old People (10BRK010) ;Research on the Construction of Rural Community Old-age System in Shaanxi Rural Areas from the Perspective of Social Network(2015KRM079).

\section{References}

[1] Zhou Xianglian, Lian Jianxin. Research on the development of rural home care service under the perspective of service-oriented government [J]. Hunan Social Sciences, 2013, (5): 124-127.

[2] Zhou Yuanpeng, Zhang Fuxiu. The Practice and Thinking of Promoting Community Old-age Service in Community - Based on the Survey of Typical Communities [J]. Science Development, 2012, (12): 72-75.

[3] Xu Zhiwen, Xie Fang. Analysis on the Rationality of Providing for the Aged in Rural Community and Its Implementation Countermeasures [J]. Rural Economy, 2005 (11): 73-75.

[4] Li Hongxin, Li Wei. A Study on the Pattern of Providing for the Aged at Home and Abroad [J]. Economics and Management, 2012, (12): 18-22.

[5] Liu Yan. A Study on the Influence of Social Capital on Rural Old People 's Willingness to Participate in Community Service for the Aged[D]. Jinan: Shandong University of Finance and Economics, 2015.
[6] Zhao Zhiqiang, Yang Qing. The Mode of Providing for the Aged in Rural Areas from the Perspective of Institutional Embedding[J]. Rural Economy, 2013, (1): 24-26.

[7] Han Zhenqiu. A Brief Analysis of the New Pattern of Providing for the Aged in the Countryside [J]. Journal of Theoretical Studies, 2013, (11): 80-82.

[8] Gao Herong, Zhang Aimin. China's traditional forms of mutual support and its value - based on the survey of southern Fujian [J]. Shandong Social Sciences, 2014, (4): 142-143.

[9] Zhao Zhiqiang. The Development Dilemma and Tactics of Rural Mutual Aid and Old - age[J]. Journal of Hebei University, 2015, (1): 34-35.

[10] Parrott Lester. Social Work and Social Care[M]. London: New York Rourledge, 2003.

[11] Alan Walker. Community Care: The Fanuly, the State and Social Policy[M]. London: Basil Blaek well, 2005.

[12] Skellie FA, Mobley GM and Coan RE. Cost-effectiveness of community-based long-term care: current findings of Georgia, alternative health services Project[J]. American Journal of Public Health,2008,72(4):353-358.

[13] Pillemer Karl, Macadam Margaret, \& Wolf Rosalies. Services to families with dependent elders[J]. Journal of aging \& socialpolicy,2009, 42(3):67-88.

[14] Rosalie A Kane. Community supports, home care, and long-term services Looking sideways and backwards for insights on long-term care for older people[J]. The Gerontologist, 2010, 25(4):23-36. 